\title{
BMJ Open Beliefs and challenges held by medical staff about providing emergency care to migrants: an international systematic review and translation of findings to the UK context
}

\author{
Hooi-Ling Harrison, ${ }^{\circledR 1}$ Gavin Daker-White ${ }^{\circledR 2}$
}

To cite: Harrison H-L, DakerWhite $\mathrm{G}$. Beliefs and challenges held by medical staff about providing emergency care to migrants: an international systematic review and translation of findings to the UK context. BMJ Open 2019;9:e028748. doi:10.1136/ bmjopen-2018-028748

- Prepublication history and additional material for this paper are available online. To view these files, please visit the journal online (http://dx.doi org/10.1136/bmjopen-2018028748).

Received 28 December 2018 Revised 3 June 2019 Accepted 5 June 2019
Check for updates

(C) Author(s) (or their employer(s)) 2019. Re-use permitted under CC BY-NC. No commercial re-use. See rights and permissions. Published by BMJ.

${ }^{1}$ Emergency Department, Princess Royal University Hospital, King's College London School of Medical Education, London, UK

${ }^{2}$ Centre for Primary Care, University of Manchester, Manchester, UK

Correspondence to Dr Hooi-Ling Harrison; hlingharrison@hotmail.co.uk, hooi-ling.harrison@kcl.ac.uk

\section{ABSTRACT}

Objective Migration has increased globally. Emergency departments (EDs) may be the first and only contact some migrants have with healthcare. Emergency care providers' (ECPs) views concerning migrant patients were examined to identify potential health disparities and enable recommendations for ED policy and practice.

Design Systematic review and meta-synthesis of published findings from qualitative studies.

Data sources Electronic databases (Ovid Medline, Embase (via Ovid), PsycINF0 (via OVID), CINAHL, Web of Science and PubMed), specialist websites and journals were searched.

Eligibility criteria Studies employing qualitative methods published in English.

Settings EDs in high-income countries.

Participants ECPs included doctors, nurses and paramedics.

Topic of enquiry Staff views on migrant care in ED settings.

Data extraction and synthesis Data that fit the overarching themes of 'beliefs' and 'challenges' were extracted and coded into an evolving framework. Lines of argument were drawn from the main themes identified in order to infer implications for UK policy and practice. Results Eleven qualitative studies from Europe and the USA were included. Three analytical themes were found: challenges in cultural competence; weak system organisation that did not sufficiently support emergency care delivery; and ethical dilemmas over decisions on the rationing of healthcare and reporting of undocumented migrants.

Conclusion ECPs made cultural and organisational adjustments for migrant patients, however, willingness was dependent on the individual's clinical autonomy. ECPS did not allow legal status to obstruct delivery of emergency care to migrant patients. Reported decisions to inform the authorities were mixed; potentially leading to uncertainty of outcome for undocumented migrants and deterring those in need of healthcare from seeking treatment. If a charging policy for emergency care in the UK was introduced, it is possible that ECPs would resist this through fears of widening healthcare disparities. Further recommendations for service delivery involve training and organisational support.
Strengths and limitations of this study

- This review performed a thematic meta-synthesis of qualitative studies to enable a deeper understanding and exploration of emergency care providers (ECPs) beliefs and challenges surrounding the provision of care to migrants.

- All studies reached theoretical saturation.

- If the study results did not separate out ECPs responses from other healthcare professionals, they were excluded, potentially missing key data.

\section{INTRODUCTION}

\section{International context}

International migration is at its highest ever level and increasing, with the 2017 estimate at $3.4 \%$ (258 million people) of the global population, a $49 \%$ increase since $2000 .^{1}$ The UK experienced significant migration during the 1970s after joining the European Union (EU) and between 1993 and 2015, the foreign-born population more than doubled from 3.8 to 8.7 million $(7 \%-13.5 \%)$ with a peak net increase of 336000 in 2015 during the European migration crisis. The UK immigration figures currently sit among the top five countries in the world. ${ }^{1}$ While most migration occurs legally, there were an estimated 533000 undocumented migrants (UMs) in the UK in 2007. ${ }^{23}$

\section{Definitions}

There is no apparent consensus on the definition of a migrant which makes drawing scientific conclusions based on the data challenging. ${ }^{4}$ For this review, the terminology in table 1 was used to ensure clarity and consistency.

Migrant health as a public health concern The majority of migrant populations are healthy when they arrive, however, a number, 
Table 1 Migrant terminology

First-generation migrant Second-generation migrant

Asylum seeker

Refugee

Undocumented migrant
Foreign-born resident who has become a citizen or permanent resident in a new country. Naturally born to one or more parents who were born elsewhere.

A person who has left their country of origin and formally applied for asylum in another country but whose application for refugee status has not yet been concluded.

The asylum seeker has their claim for asylum accepted by the government.

Foreign-born person with no legal right to stay in the host country. These include: persons who have entered illegally, failed asylum seekers, overstayers (migrants who remain in the host country after their resident permit or visa has been revoked or expired), undocumented by birth (born into a family who have no legal right to stay). particularly, refugees, asylum seekers and UMs suffer a disproportionate burden of morbidity. ${ }^{5}$ Providing effective healthcare for migrants is of key public health importance, not only for treating the individual, but also in reducing the spread of communicable disease and the impact of future non-communicable diseases on the economy.

\section{The key role of emergency departments in migrant healthcare} The UK National Health Service (NHS) emergency services play a key role in the nation's public health as the first and only contact some migrants may have with the health system. However, emergency departments (EDs) are overstretched with yearly increases in patient presentations. The '4-hour target', a proxy measurement of system effectiveness has not been met since 2015. Some UK politicians have quoted migrants as a causative factor, ${ }^{6}$ which has fed a media debate about eligibility for care. A recent systematic review has demonstrated that in Europe, migrants use EDs more than the native population, often for lower acuity presentations. ${ }^{7}$ Most migrants, however, comprise a healthy labour force, and make a positive overall contribution to the exchequer.

\section{The issue of charging non-British citizens for emergency care} In an effort to recover costs to the NHS, charging non-British citizens for secondary healthcare is the current practice, as per the 2016 Immigration Act. Extension of this into emergency care has been proposed, challenging the NHS's three core principles that it should meet the needs of everyone, it should be free at the point of delivery and it should be based on clinical need, not on the ability to pay. ${ }^{8}$ Healthcare advocacy groups have warned about the potential impact on the most marginalised populations. ${ }^{910}$ In this climate of the pressurised ED where migrants are portrayed as a burden, and the identification of paying 'customers' and UMs is expected, ED providers' views towards migrant patients could point to whether health disparities exist, as in the way patients are handled or dealt with.

\section{Staff attitudes and cultural competencies}

There are no qualitative studies examining the emergency care provider (ECP) perspective of providing emergency care to migrants in the UK. In Denmark, two surveys based in the ED found that less satisfaction was expressed by healthcare professionals (HCPs) when patients were non-Western, and when the visit was felt to be less relevant. ${ }^{11}$ Most of participants knowledge on migrants came via the media. ${ }^{12}$ Other studies identified challenges surrounding language and cultural differences, time constraints, lack of awareness by healthcare staff of what health services were available to the migrantespecially UMs - and lack of healthcare connectivity. ${ }^{13}$ Although some HCPs have expressed desirability for cultural competence, some felt it was the responsibility of migrants to adapt to the local context. ${ }^{14-16}$ 'Cultural competence' has been defined as, 'an overall ethos of awareness and openness towards diversity,' as opposed to assumptions concerning the values or behaviour of particular groups. ${ }^{14}$

\section{Study aims and objectives}

The primary objective of the study was to synthesise findings concerning ECPs beliefs and challenges for providing healthcare to migrants as found in reports of research studies based in high-income settings. The notions 'beliefs' and 'challenges' were based on the results of pilot searches which suggested these metathemes as a good way of organising the extant literature. 'Beliefs' is here shorthand for staff views and opinions in relation to the perceived presentation, motivations and behaviour of migrants (according to the definition presented above) in EDs. What do migrants need? What is the clinical presentation? How do they conduct themselves? 'Challenges' relates more to the staff or institutional response, or the 'fit' (or lack of it) between system or cultural expectations and migrant behaviour. Pertinent issues would include language translation, and presence of relevant identity documents (as required by individual services).

A secondary aim was to relate the findings to current NHS policy and practice. The issue of charging patients in $\mathrm{ED}$, a current UK policy proposition, was to emerge as an underlying consideration in the extracted findings from the studies. In a process, the authors have labelled 'translation', the study findings were, therefore, reflected against these current proposals in order to imagine the potential consequences of charging migrants for ED care in the UK or other high-income country contexts. 
Table 2 Inclusion and exclusion criteria

\begin{tabular}{|c|c|}
\hline Inclusion criteria & Exclusion criteria \\
\hline \multicolumn{2}{|l|}{ Studies published from any time point } \\
\hline English language & Non-English language \\
\hline $\begin{array}{l}\text { Emergency care provider=nurse, doctor, paramedic, } \\
\text { healthcare assistant }\end{array}$ & $\begin{array}{l}\text { Other secondary healthcare providers seeing emergency patients for } \\
\text { example, doctors assessing acute stroke or orthopaedic surgeons } \\
\text { assessing fractures, even if in the ED. Primary healthcare providers }\end{array}$ \\
\hline $\begin{array}{l}\text { Based in the emergency department (ED) or 'prehospital } \\
\text { emergency' field }\end{array}$ & $\begin{array}{l}\text { Out of the ED or prehospital environment, } \\
\text { for example, cardiologists performing PCls in a catheter laboratory, } \\
\text { primary care, outpatients, hospital wards }\end{array}$ \\
\hline
\end{tabular}

$\mathrm{PCl}$, Percutaneous Coronory Intervention.

\section{METHODS}

A systematic review of studies of ECPs attitudes to migrant care in high-income country settings was undertaken. Qualitative meta-synthesis was used as an organising and analytical frame for findings extracted from included studies. Qualitative studies were selected from high-income settings such as (Western) Europe, North America and Australasia to facilitate potential generalizability to the UK. The specific inclusion and exclusion criteria are shown in table 2 .

\section{Information sources}

The search for relevant texts involved databases, websites, conference proceedings, abstracts, policy documents and book chapters. ${ }^{17}$ The bibliographic databases searched were: Ovid Medline, Embase, PsycINFO; CiNahl, Web of science, PubMed, Trip database and Google scholar. The Websites of WHO, The Migration Observatory, the International Organisation for Migration, the Department of Health and Social Care (DHSC) (UK), Public Health England and Doctors of the World (DoW) were searched, along with the emergency medicine specific websites: Life In the Fast Lane and Royal College of Emergency Medicine (RCEM) learning.

Backward and forward searching through the references lists and the citations for all eligible papers was undertaken to identify any further studies. A handsearch through the three highest impact emergency care journals: the UK Emergency Medicine Journal, the European Journal of Emergency Medicine and the Journal of Emergency nursing, was conducted as well as a search for unpublished grey literature.

The primary searches were performed between 1 February 2018 and 31 March 2018. The bibliographic database searches were rerun during the article submission process to find additional relevant material. In this manner, Ovid Medline, Embase (via Ovid), PsycINFO (via OVID), CINAHL, Web of Science, PubMed, Trip Database and Google Scholar were all searched again (using the original searches) on 16 March 2019 and no additional studies were found.

\section{Search}

Key databases were searched using a refined range of keywords and terms individually and then in combination using Boolean operators 'AND/OR' to ensure searches were sensitive and specific. ${ }^{18}{ }^{19}$ Although specifically looking for beliefs and challenges, broader search terms were used. An example of the Medline search is shown in table 3 (further search terms in online supplementary appendix 1).

\section{Study selection process}

Two reviewers (H-LH, GD-W) independently scanned titles. If relevant, abstracts were then screened against the inclusion criteria. Full texts were obtained for the screened list of abstracts to further assess eligibility. Both authors assessed their inclusion for reliability. Several articles were reported under the umbrella of 'Best Practice in Health Care Services for Immigrants in Europe (EUGATE)' (table 4). These were treated as different studies as they employed different participant subsets and analytical sampling frames.

\begin{tabular}{ll}
\hline Table 3 & Medline search \\
\hline Database & Ovid (1946 onwards) Medline \\
\hline Search terms & $\begin{array}{l}\text { Exp emergency service, hospital/orexp } \\
\text { emergency medical services/or emergency care } \\
\text { provider or exp emergency medicine/or exp } \\
\text { emergency nursing/or exp emergency nurse }\end{array}$ \\
& $\begin{array}{l}\text { AND } \\
\text { Exp emigrants and immigrants/orexp } \\
\text { transients and migrants/or exp refugees/orexp } \\
\text { undocumented immigrants/orasylum seeker/ } \\
\text { ordisplaced person }\end{array}$ \\
& 436 \\
\hline Results &
\end{tabular}




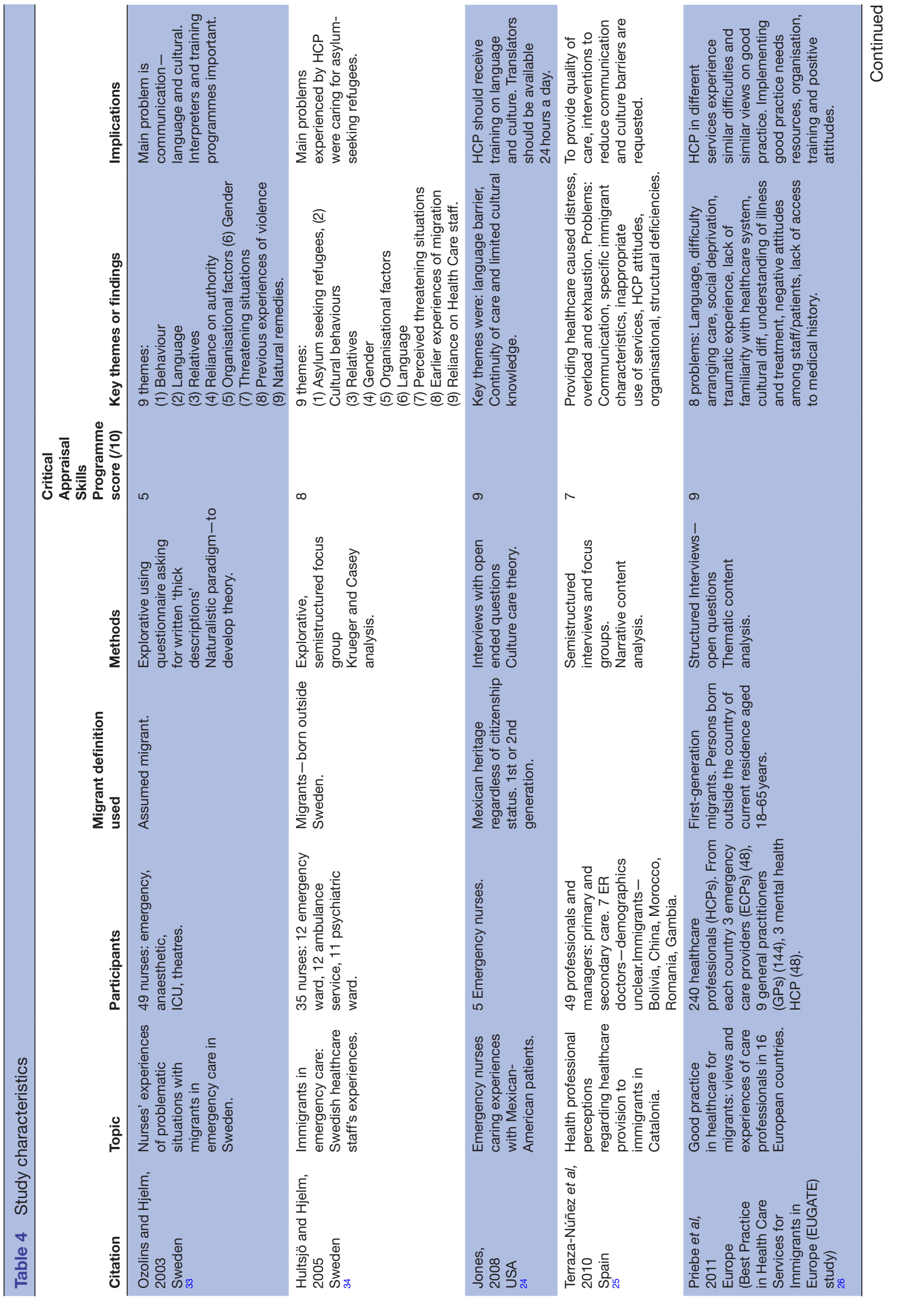




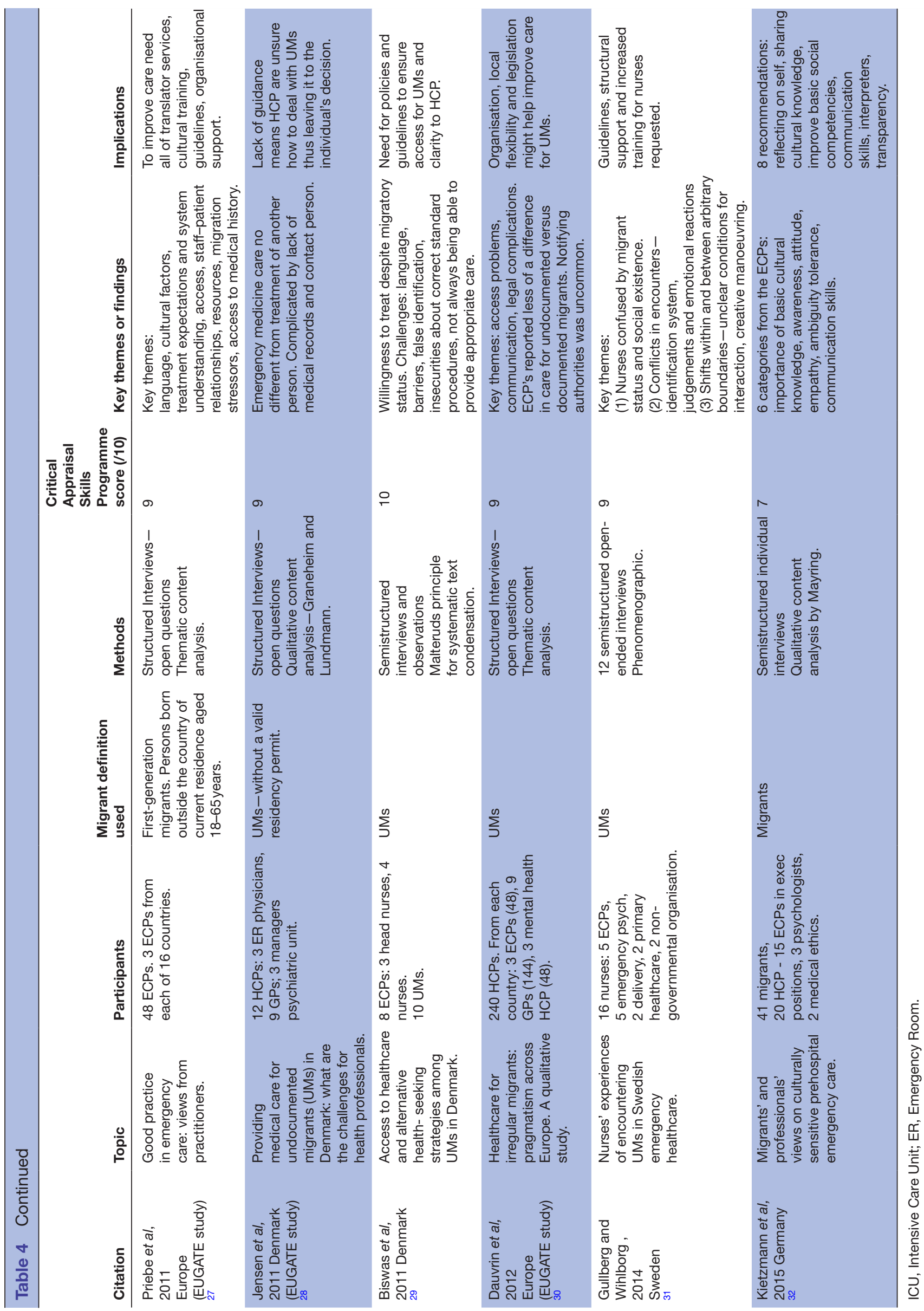




\section{Data extraction process}

Study data were collected and tabulated in an Excel spreadsheet. Where studies included other populations, such as general practitioners, only results clearly pertaining to ECPs were extracted. Following a pilot phase, data were extracted by H-LH.

To facilitate the systematic synthesis of results, all extracted data were inputted into an Excel spreadsheet under two columns: 'beliefs' and 'challenges'. Papers were read line by line, relevant lines were extracted and entered under the headings and coded into themes, akin to framework analysis in primary qualitative research. ${ }^{20}$ Subsequent studies were coded into pre-existing concepts and new ones were formed when possible. The papers were reread several times to ensure all data was extracted and codes were revised if new information was found that required a modification. The findings from this iterative process were discussed between both authors on a periodic basis in order to refine the coding schema and conceptual understanding of the themes.

\section{Quality appraisal}

All studies were subject to quality assessment scoring as per the qualitative Oxford Critical Appraisal Skills Programme (CASP) assessment tool of ten questions. Only studies that answered 'yes' to the first two screening questions were included. ${ }^{21}$ Although a total CASP score out of ten was given for each study (see table 4), due to the nature of qualitative research the scores were not used to weight the papers. Papers were assessed according to ability to answer the research question. ${ }^{18}$

\section{Synthesis of results}

Codes were grouped inductively into cross-cutting themes to enable deeper interpretation of what the beliefs and challenges were. A meta-synthesis was conducted by aggregating and summarising the studies in order to produce themes that could introduce larger interpretations into how the beliefs and challenges could affect emergency careprovision in the high-income country context. $^{22}$ Drawing on this synthesis, a translation to the UK NHS context, with reference to other literature, law and policy was undertaken.

\section{Patient and public involvement}

Patients and the public were not involved in this review.

\section{RESULTS}

A total of 4185 studies were found of which 11 were deemed relevant and included. The Preferred Reporting Items for Systematic Reviews and Meta-Analyses flow diagram (figure 1) demonstrates the search process with reasons for study exclusion. ${ }^{23}$

\section{Study characteristics}

Eleven qualitative studies, published between 2003 and 2015, were included: one from the USA and the remainder from Western European countries. Four studies came from the EU-funded EUGATE study group table 4.

\section{Risk of bias}

First and second-generation migrants were studied, however, as how ECPs identified them as such was unclear, the risk of stereotyping was evident. Only 8 of the 11 studies detailed the decision behind choice of population, stating the reasons as migrant load and ECP exposure to migrants. ${ }^{24-31}$ Populations of high migrant contact may demonstrate more compassionate behaviour than areas of less contact or, be able to self-regulate whether an experience is specific to a migrant. Conversely high burden areas may feel under higher pressure, with limited resources and feel more negatively towards migrants. Only three papers commented on the origin and ethnicity of the ECP. ${ }^{24} 3132$ It should be acknowledged that an ECP from a migrant background might respond more favourably towards a migrant patient as compared with a non-migrant ECP. One study ${ }^{33}$ used an explorative questionnaire with open-ended questions, enabling thick descriptions but missing opportunity to clarify points, which the remaining studies using interviews benefited from. However, these risked response bias, such as through not admitting the denial of care to an UM for risk of seeming socially undesirable.

Five studies asked about experiences caring for migrant patients, and five asked for specific problems migrants may pose, suggesting that immigrants are already problematised and perhaps leading to more negatively biased responses. Terraza-Núñez et al's study ${ }^{25}$ was the only study to describe triangulation of results through comparing data from different sources and groups of informants. All qualitative studies by their nature risk recall bias and there was no mention of self-reflexivity in any of the papers, which could create interviewer bias. All studies reported that theoretical saturation was reached.

Most studies were undertaken in EU countries and this, together with the issues raised above, indicates that if the findings were easily synthesizable, there is fairly high confidence that they represent a valid picture of the perceptions of ED staff working in a Western European context.

\section{Study quality}

The explorative questionnaire study returned the lowest CASP score (see table 4), perhaps highlighting the hybridised nature of the method, although an open-ended questionnaire schedule might be considered 'qualitative' on a continuum. The findings were nevertheless found to fit with those from other studies and the article was not excluded. The remaining studies scored between 7 and 10 according to the CASP checklist. Typically, articles failed to discuss researcher-participant relations; although this is not unusual in applied research concerning health services. Overall, the reporting quality of the studies was high, with 7 of the $11(63.63 \%)$ scoring 9,10 or higher. 


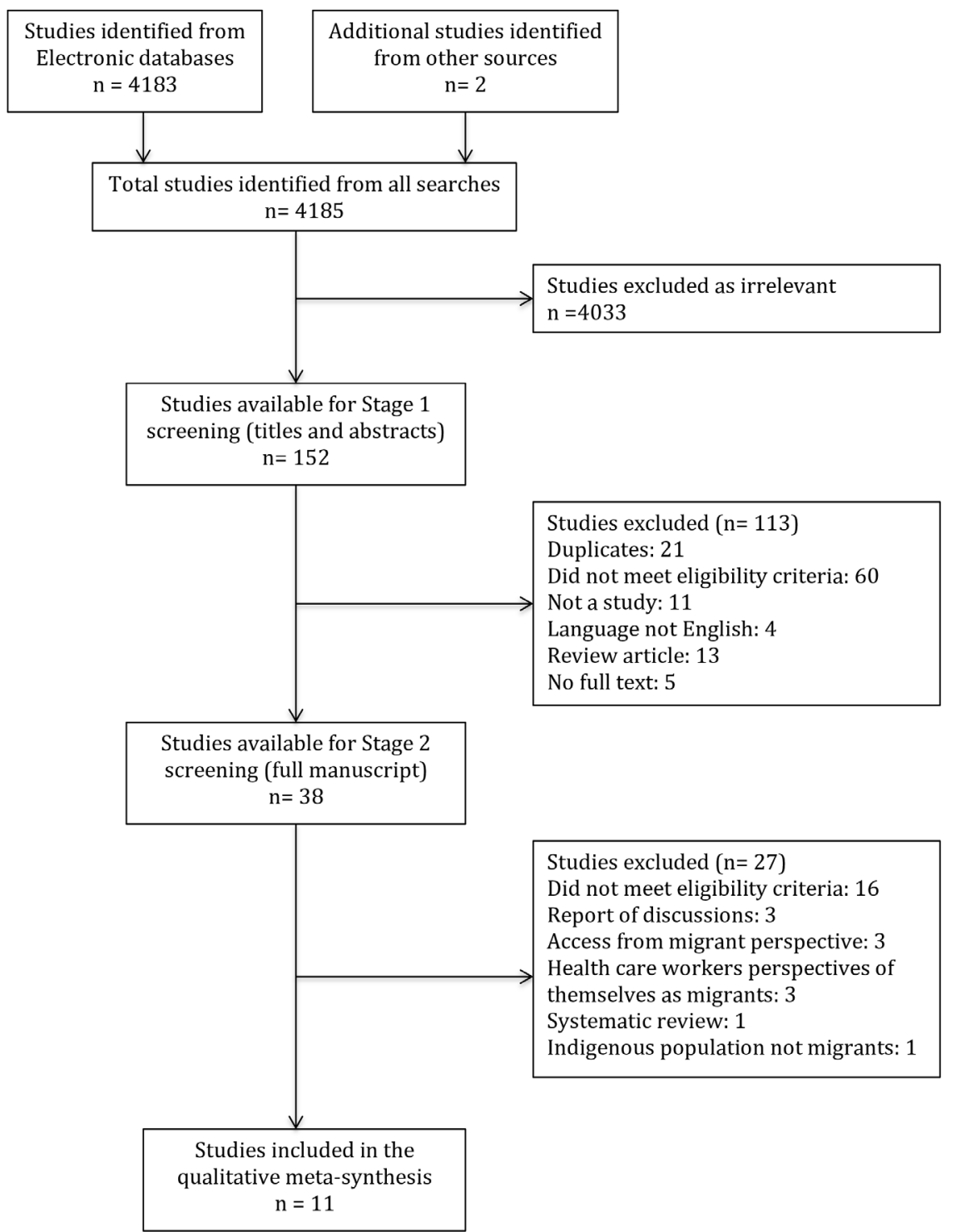

Figure 1 PRISMA diagram of included and excluded studies. PRISMA, Preferred Reporting Items for Systematic Reviews and Meta-Analyses.

\section{Thematic synthesis results of the beliefs and challenges}

Three overarching analytical themes were found: cultural competence, system organisation and ethical dilemmas. These are described below.

\section{Cultural competence}

On the basis of their experiences of treating migrant patients, difficulties were identified around potential clinical misunderstanding due to the social distances often involved. These issues coalesced around communication, (associated) problems in the clinical reading of patient behaviour and differing social expectations. The latter principally involving interpersonal gender dynamics and respect for medical authority. Staff felt this power imbalance and constructed stereotypes of migrants as they encountered the difficulties outlined below.

\section{Language}

Communication difficulties meant that some ECPs felt unable to make an assessment of severity of illness leading to over or under investigation and potential mismanagement. ${ }^{34}$ For example, in one case it was unclear whether a patient was unconscious or just did not understand Swedish. ${ }^{33}$ Struggling to articulate advice to the patient led to frustration on both sides. ${ }^{28}{ }^{34}$ The use of relatives or close friends as interpreters was felt to be suboptimal. ${ }^{2433} 34$ The use of professional interpreters was stated as good practice $24262832-34$ although accessing them 24 hours a day was difficult. ${ }^{24}$

\section{Behaviour}

ECPs found certain migrant behaviours difficult to comprehend. For example, screaming during venesection $^{33}$ and staying silent following bereavement were 
perceived as over and under reactions by ECPs. ${ }^{24}$ This risked mismanagement, such as the case of a migrant suffering a cardiac event who was believed by the ECP to be over exaggerating to keep a single room. ${ }^{33}$ Or the migrant who complained of chest pain believed to have had a heart attack, but was actually displaying an acute stress response to past events of torture and conflict. ${ }^{34}$ Aggressive and problematic patient behaviour was noted by ECPs,${ }^{33}$ however, two studies also reported, negative attitudes and hostile behaviour by staff towards migrant patients. $^{2627}$

\section{Gender}

The importance of migrant gender dynamics and need to find healthcare providers of the appropriate sex was respected by ECPs. However, ECPs found male migrants speaking for female patients uncomfortable, and, female ECPs found male migrants who lacked trust in their abilities, frustrating. ${ }^{30} 3334$ Importantly, in an emergency, ECPs stated that delivering emergency care would take priority over finding an ECP of the required gender. ${ }^{27}$

\section{Respect for authority}

Some Swedish emergency nurses perceived that migrants had less respect for them compared with for physicians, by questioning their competence and refusal of treatment. $^{31} 3334$ Conversely, nurses managing Hispanic patients in the $\mathrm{USA}^{24}$ experienced only appreciation towards them. This is in line with Hispanic cultural ethos of respeto, towards authority and suggests that challenges are likely to be migrant specific, or related to the nature and culture of the host nation. ${ }^{24}$ ECP's stated that ethnically diverse ECPs are beneficial to managing a migrant population. ${ }^{26}$

\section{Relatives}

Large numbers of relatives created a disruptive environment and disagreements on care between the ECP and relatives, was occasionally described, creating a hindrance to optimal patient care. ${ }^{33}$ However, ECPs did acknowledge the importance of strong family links for gaining a collateral history and social support. ${ }^{24} 2627$

\section{Stereotypes}

ECPs often portrayed migrants, in particular UMs, as being of low socioeconomic status, perhaps struggling to integrate, engaged in misuse of drugs and alcohol, sex work or crime; reflecting their socially marginalised and stigmatised status. ${ }^{26} 2734$ Some perceived UMs as a burden on society through not working or having a child to attempt to gain access to (in this case) Swedish citizenship. However, some ECPs were concerned at being portrayed as a racist by a migrant if their care seemed not to be fairly prioritised. ${ }^{34}$ Interestingly, ECPs felt that migrants perceived them to be in positions of power, holding the autonomy to make decisions about their healthcare as well as their migration status (through access to documentation or conversely power to report to the authorities). ${ }^{2631}$

\section{System organisation}

The difficulties and stereotypes described above-led ECPs to form explanations, not only for migrant health seeking behaviour and presentation, but also for the legal or organisational contributors to the perceived behaviour. The primary issues concern problematics related to the timely use of ED by migrants, seen as realistically the "only option' for healthcare and the opacity of arrangements around an individual migrant's legal status and access to other health services.

\section{Migrants use of the health system}

ECPs constructed a view of migrants as having lower education and health knowledge, thereby lacking understanding of the host country's health system. They associated this with perceived suboptimal health behaviours. They were more likely to call an ambulance or attend ED frequently for non-acute medical problems. ${ }^{25273334}$ Other perceived migrant behaviours, such as late presentation, were seen to reflect social vulnerability and reduced primary care access. ${ }^{28}$ Interestingly, negative media portrayal of migrants was also seen as a factor for migrants not wanting to appear troublesome by attending EDs. ${ }^{26}$ ECPs recognised that for UMs, fear of being reported to the authorities delayed them from seeking healthcare $^{24-262931}$ and were frustrated that this delay sometimes led to deterioration of illness. ${ }^{27}$ ECPs felt that certain health conditions were not disclosed, for fear of requiring referral to inaccessible services ${ }^{29}$ and that often the ED is the only option for UMs to seek healthcare. ${ }^{26}$

\section{Organisational support for UMs}

ECPs expressed uncertainty on providing emergency and ongoing care to UMs due to a lack of or unclear guidance for the circumstances of no residency status or insurance. ${ }^{25-28} 3133$ Guidelines in existence were open to interpretation, leading to subjective management and potential for ECPs to exert 'power' in decision making. ${ }^{2831}$ ECPs recognised this lack of consistency would lead to anxiety by UMs when accessing healthcare. UMs were often noted to not attend appointments for fear of being reported to the authorities. ${ }^{31}$ ECPs that attempted referral of UMs onto the welfare system found that the migrant was not adequately supported, which increased ECP disillusionment with the system. ${ }^{33}$

\section{Ethical dilemmas}

Migrant patients were seen to impose ethical dilemmas on ECP staff in EDs. In common with views expressed above, it was universally accepted that the decision to provide care would always be taken without other considerations, although a decision to inform the authorities appeared to operate more on a case-by-case basis which took other factors into account. Other dilemmas surfaced around fair use of health resources in the context of underfunding and where some patients were perceived to be 'gaming' the system to assist with applications, for example, for refugee status. 
Immigration status does not affect emergency care

ECPs claimed that immigration status would not affect their decision to provide emergency care. ${ }^{24}$ 28-31 However, legal versus ethical and professional conflicts are experienced by ECPs on whether to inform the authorities about UMs. Some ECPs removed the decision from their role believing it was not their responsibility to decide, ${ }^{29} 31$ for example, one such attitude taken was '[I] don't ask so [I] don't have to make the decision'. ${ }^{28}$ There were some situations where ECPs were more likely to inform the police, such as when they suspected a serious crime was involved or if the patient was a danger to themselves. ${ }^{27} 2830$

\section{Health professionals as gatekeepers}

ECPs recognised the increased resources, such as diagnostic tests and administrative time, required to manage non-resident migrant or UM patients. ${ }^{26-28} 3034$ ECPs, therefore, felt compelled to consider the ethics of rationing the service. In some contexts, prepayment of the full fee was demanded in cash, in accordance with rules for foreigners. ${ }^{31}$ In others, health services, such as non-governmental organisations were used as an alternative provision of care. ${ }^{2730}$ Many ECPs felt that more funding for this patient group would improve their ability to provide adequate patient care. ${ }^{27}$

\section{Gaming}

Some ECPs perceived asylum seekers to feign illness and fake documentation in order to obtain medical certificates to support asylum and residency permit applications. Some ECPS felt this behaviour to be dangerous and foolish, however, many expressed helplessness at being unable to assist. ${ }^{3133}$ Individual clinicians attempted to game the system using fake social security numbers, submitting laboratory samples in their own name and prescribing cheaper (or giving out free samples) of medicine. $^{26-2830}$

\section{DISCUSSION}

This study set out to review and synthesise findings related to the perceived 'beliefs and challenges' of migrant care, as articulated by ECPs in findings of published, primary qualitative studies. Eleven studies published during 2003-2015 were included, although one (which was borderline according to both inclusion criteria and CASP score, see table 4) was only partly qualitative in that an open-ended questionnaire was used. The remainder were of high reporting quality and most were undertaken in Western European countries. The thematic synthesis of findings extracted from the primary studies found that they comprised three main themes: cultural competence, organisational contributors to the perceived problematics of migrant care and ethical dilemmas. The question of charging patients emerged as an issue which cut across several aspects of clinical management, although ECPS were adamant that in an emergency, giving treatment would always trump other considerations.

\section{Limitations}

Studies which included ECPs but did not separate out their responses from other health professionals were excluded, potentially missing valuable material. However, the authors argue that this focus strengthens the validity of the findings so far as ED workers in Western European contexts are concerned. This focus means it is also important to stress that the staff views expressed in the studies relate solely to users of EDs, who are likely to be unrepresentative of the total migrant population in the local area in question. There was mixed representation of different ECP occupational groups across the studies, potentially biassing conclusions made. Only studies of ECPs were included in the review and the beliefs of counsellors, administrative staff, receptionists, porters and others who may influence the migrant experience of the ED and decision-making around the use of emergency care were not considered. Finally, the data were extracted by one author only, although in practice the review and synthesis process entailed reading each included study report several times over.

\section{Findings}

All ECPs described the cultural challenges of a language barrier, migrant behaviour that was unusual for the host country and gender dynamics. In some instances challenges were met relating to migrant respect for authority and the number of relatives. ECPs expressed that these challenges can lead to frustrations, delays in care, and risked the mismanagement of patients. These findings are not unsurprising, and similar issues have been described frequently in UK literature going back over 25 years. ${ }^{35}$ However, this apparent lack of progress is concerning. Stereotyping of migrants was largely evident and it is well documented that this can occur implicitly in high-pressure crowded environments, such as the ED. ${ }^{36}$ It was interesting that migrants were often stereotyped as being from the lower socioeconomic classes and of marginalised status, ${ }^{31}$ which, although true for some populations, the majority will have regular jobs and contribute to society. This perhaps reflects the wider societal concerns about asylum seekers and economic migrants who enter illegally, for example, in relation to the 2010 Arab Spring where ECPs may have had first-hand experience of a large influx of refugees and exposure to negative media footage.

ECPs perceived that some migrants, particularly from lower socioeconomic backgrounds, lacked understanding of the host country's health system, leading to inappropriate access of services, supporting the finding in a recent systematic review of migrant use of EDs in Europe. ${ }^{37}$ However, it is important to note that this behaviour is not only isolated to migrant groups but is seen in lower socioeconomic populations lacking health insurance. ${ }^{38}$ ECPs also expressed a lack of migrant health knowledge, however, the concept of a parallel migrant care health system was rejected due to the risks of an unintegrated 
service that worsens social isolation, an opinion shared by WHO. 273940

With over 300 different languages spoken by London's school children in 2015, ${ }^{41}$ and an estimated $500000 \mathrm{UMs}$, maintaining cultural competence and organisational support within the NHS is essential. The ECPs in this review recognised the need for this, ${ }^{24-34}$ however, only a minority ${ }^{26-2830}$ reported that their service had sufficient human and technical resources to support it, suggesting an inability to meet rapid migration changes. Within the UK, equality and diversity training for healthcare workers, interpreter services and resources such as the DHSC 'migrant health' webpage ${ }^{42}$ are among initiatives supporting clinicians. Additionally, one-quarter of the NHS health workforce are migrant born. ${ }^{43}$ Importantly, this workforce diversity improves compassion and the skills required to care for migrant patients. ${ }^{44}$ Unfortunately, anecdotal evidence since the 2016 EU referendum suggests that increasing numbers of migrant workers are leaving the NHS, although how this specifically impacts on EDs is as yet unknown given wider pressures on the service.

\section{Ethical dilemmas when treating UMs'}

All ECPs in this review reported a lack of guidance or support in the context of law and governance policies relating to the management of UMs. The Geneva Declaration, 1948 stated that 'It is the duty of a doctor to be dedicated to providing competent medical service in full professional and moral independence, with compassion and respect for human dignity. ${ }^{45}$ However, the ECP faces an ethical, moral and legal dilemma: a choice to treat an UM could move scarce resources away from someone else in greater need. On the other hand, the rationing of resources and not treating an UM risks widening health inequalities. A choice to inform the authorities will almost certainly mean deportation. Emergency care to migrants was not withheld at any of the study sites, even within the chargeable contexts (Finland, Sweden and USA). However, for UMs, there was mixed opinion on informing the authorities and willingness to 'game the system' to enable ongoing care.

The Home Office actively seeks UMs in the UK and formally used a data-sharing agreement with NHS Digital to collect relevant data. This was abandoned following interventions from health and civil liberties groups. ${ }^{46}$

Reliance for recognising and reporting UMs now falls on HCPs when UMs access the health system. The General Medical Council and Home Office both state that the decision to report is a balance between patient confidentiality and their medical needs, weighted against the public interest. ${ }^{47}$

\section{UK policy context: NHS emergency care charging policy}

To help alleviate overstretched EDs of unnecessary attendances and to increase NHS funding, the DHSC (formerly Department of Health) has advised introducing a charging policy for non-resident migrant patients accessing emergency care. ${ }^{48}$ Several organisations (British Medical Association, Royal College of General Practice (RCGP) and DoW) state that there is limited evidence that NHS use by migrants is a substantive problem. ${ }^{40}{ }^{50}$ Activist groups, such as DoW and 'Docs not cops' have campaigned aggressively to oppose these proposals ${ }^{5152}$ stating that the policy challenges the NHS's core principles ${ }^{8}$ will affect the most marginalised populations, through inability to afford a chargeable service, leading to widening healthcare disparities and impacting on public health. Stereotyping is evident from this review and the identification of chargeable patients ${ }^{53}$ risks implicit racial profiling by ECPs, an issue which the 'UK Guidance on implementing the overseas visitor charging regulations' strongly advises against. ${ }^{48}$ The views of ECPs in this review suggest that if this policy was introduced there would be likely moral, ethical and procedural confusion for ECPs. This could lead to opposition, resistance or variable implementation of the policy for possibly spurious reasons. Currently, the medical union Doctors in Unite support health workers who refuse to check migrant patients' eligibility for NHS care before treating them, and who may face disciplinary action for doing so. ${ }^{54}$

\section{The evidence base in migrant health}

A bibliometric analysis of global research in migrant health pointed to the over-representation of studies in 'high-income destination countries, ${ }^{55}$ although only one of the cited articles was based in an ED. The reasons for the lack of such research in the UK are unclear, but future studies could be used to validate the findings presented here. The proposed 'Million Migrants study of healthcare and mortality outcomes in non-EU migrants and refugees to England, ${ }^{56}$ and other initiatives around the UCL-Lancet Commission on Migration and Health will provide better intelligence on which to base decisions about health services more broadly. ${ }^{57}$

\section{Meta-synthesis}

Two interpretations were drawn from putting the findings of the studies together. The first concerns the pre-eminent role of clinical autonomy in the delivery of migrant healthcare in the ED. A line of argument that follows from this realisation is that documentation is a secondary consideration in emergency care. Questions arise about the outcomes which could arise from instituting a charging policy.

- Clinical autonomy.

A migrant, with reduced knowledge of the host country's health system and culture, will be in a position of vulnerability. A migrants' experience will depend on the ECPs knowledge and willingness to make adjustments for them. The constraints of the 'system', that is, a pressurised ED may lead to reduced tolerance for adapting to the needs of migrants and potentially increase healthcare disparities. However, importantly, ECPs will not allow culture or tradition to impact on immediate life-saving treatment. 
Table 5 Recommendations

\begin{tabular}{ll}
\hline Recommendation $\mathbf{1}$ & Improved awareness of healthcare disparities through regular context specific migrant training. \\
\hline Recommendation 2 & Training on contextually appropriate migrant cultures and specific health conditions. \\
Recommendation 3 & Cultural and organisational support, for example, interpreters available 24hours a day. \\
\hline Recommendation 4 & Advice for emergency care providers (ECPs) on National Health Service system organisation. \\
Recommendation 5 & Accessible guidance on the law and regulations that affect the delivery of care to undocumented migrants. \\
Recommendation 6 & Awareness campaign for undocumented migrants on the law and ethical boundaries that ECPs are held to. \\
Recommendation 7 & $\begin{array}{l}\text { Implementation of a charging policy into emergency care should not occur without wide professional consultation } \\
\text { and a full public health assessment of the impacts on undocumented migrants and wider communities. }\end{array}$ \\
\hline
\end{tabular}

- Immigration status does not affect emergency care delivery by ECPs.

For UMs, the ED may be their only option for healthcare. Despite the ethical, moral and legal dilemmas experienced by ECPs when managing migrant patients, when it is an emergency ECPs will act in the patient's best interest. It is extremely unlikely that a policy to identify chargeable migrants would be accepted by ECPs. However, the variation in ongoing healthcare response and the decision on whether to report an UM to the authorities will continue to reinforce the barriers for UMs to seeking healthcare.

\section{RECOMMENDATIONS}

From this review, recommendations for health service providers and policy-makers are outlined in table 5.

\section{CONCLUSION}

This is the first qualitative meta-synthesis of ECP perceptions of beliefs and challenges to the delivery of emergency care to migrants within developed settings. The key findings that cultural, organisational and ethical barriers exist to providing optimal care are not insurmountable. However, the care delivered by ECPs will depend on their clinical autonomy and ethical stance. Charging within UK EDs appears difficult to implement against the context of the evidence presented within this review.

Several avenues for further research are indicated, beginning with a UK study in the same field, which would also assist with validating the findings of the approach adopted here. In general, there would be value in comparative studies which move beyond the general category of 'migrant' to understand the health needs of different groups. Future studies might also include the perspectives of administrative staff, who are usually the first point of contact with a patient. Finally, studies of the effects of staff views or attitudes on the health outcomes of migrant patients would help to evaluate training or initiatives, for example, aimed at furthering the cultural competencies of NHS or other health service staff.

Acknowledgements We would like to thank the assistant editor and reviewers for their helpful comments on an earlier draft of the manuscript.

Contributors H-LH conceived the idea for the review as part of a Masters dissertation. H-LH conducted the review and analysis under the supervision of GDW. H-LH wrote the manuscript with support and input from GD-W.
Funding GD-W's time was funded by the National Institute for HealthResearch (NIHR) Greater Manchester Patient Safety Translational ResearchCentre.

Disclaimer The views expressed are those of the author and not necessarily those ofthe NHS, the NIHR, or the Department of Health and Social Care.

Competing interests None declared.

Patient consent for publication Not required.

Provenance and peer review Not commissioned; externally peer reviewed.

Data sharing statement All data relevant to the study are included in the article or uploaded as supplementary information.

Open access This is an open access article distributed in accordance with the Creative Commons Attribution Non Commercial (CC BY-NC 4.0) license, which permits others to distribute, remix, adapt, build upon this work non-commercially, and license their derivative works on different terms, provided the original work is properly cited, appropriate credit is given, any changes made indicated, and the use is non-commercial. See: http://creativecommons.org/licenses/by-nc/4.0/.

\section{REFERENCES}

1. International Organization for Migration. Who is a migrant? 2018 https://www.iom.int/who-is-a-migrant (accessed 17 Aug 2018).

2. Ofice for National Statistics. Illegal immigrants in the UK - Office for National Statistics. 2018 https://www.ons.gov.uk/aboutus/tran sparencyandgovernance/freedomofinformationfoi/illegalimmigrant sintheuk (accessed 20 Aug 2018)

3. Summary of latest statistics - GOV.UK. GovUk. 2018 https://www. gov.uk/government/publications/immigration-statistics-year-endingmarch-2018/summary-of-latest-statistics (accessed 20 Aug 2018).

4. The Migration Observatory. Who Counts as a Migrant? Definitions and their Consequences. 2018 https://migrationobservatory.ox.ac. uk/resources/briefings/who-counts-as-a-migrant-definitions-andtheir-consequences/\#kp1 (accessed 17 Aug 2018).

5. Rechel B, ed. Migration and Health in the European Union: European Observatory on Health Systems and Policies Series, 2011.

6. McDuff P. So politicians are blaming immigrants for the NHS crisis. How predictable: The Guardian, 2017. https://www.theguardian.com/ commentisfree/2017/jan/11/immigrants-nhs-crisis-underfundingsocial-care-hospitals. (accessed 19 Jan 2018).

7. Credé SH, Such E, Mason S. International migrants' use of emergency departments in Europe compared with non-migrants' use: a systematic review. Eur J Public Health 2018;28:61-73.

8. National Health Service. Principles and values that guide the NHS. 2018 https://www.nhs.uk/using-the-nhs/about-the-nhs/principlesand-values/ (accessed 20 Aug 2018).

9. Gentleman A. Crackdown on migrants forces NHS doctors to "act as border guards". The Guardian 2017 https://www.theguardian.com/ uk-news/2017/apr/20/crackdown-migrants-nhs-doctors-borderguards-immigration-undocumented-migrants (accessed 20 Aug 2018).

10. Hiam L, Mckee M. Making a fair contribution: is charging migrants for healthcare in line with NHS principles? J R Soc Med 2016;109:226-9.

11. Mygind A, Norredam M, Nielsen AS, et al. The effect of patient origin and relevance of contact on patient and caregiver satisfaction in the emergency room. Scand J Public Health 2008;36:76-83.

12. Michaelsen J, Krasnik A, Nielsen A, et al. Health professionals' knowledge, attitudes, and experiences in relation to immigrant patients: a questionnaire study at a Danish hospital. Scand J Public Health 2004;32:287-95. 
13. Abbott S, Riga M. Delivering services to the Bangladeshi community: the views of healthcare professionals in East London. Public Health 2007;121:935-41.

14. Lindenmeyer A, Redwood S, Griffith L, et al. Experiences of primary care professionals providing healthcare to recently arrived migrants: a qualitative study. BMJ Open 2016;6:e012561.

15. Suphanchaimat R, Kantamaturapoj K, Putthasri W, et al. Challenges in the provision of healthcare services for migrants: a systematic review through providers' lens. BMC Health Serv Res 2015;15:390.

16. Robertshaw L, Dhesi S, Jones LL. Challenges and facilitators for health professionals providing primary healthcare for refugees and asylum seekers in high-income countries: a systematic review and thematic synthesis of qualitative research. BMJ Open 2017;7:e015981.

17. Booth A. Searching for qualitative research for inclusion in systematic reviews: a structured methodological review. Syst Rev 2016;5:74.

18. Atkins $\mathrm{S}$, Lewin $\mathrm{S}, \mathrm{Smith} \mathrm{H}$, et al. Conducting a meta-ethnography of qualitative literature: lessons learnt. BMC Med Res Methodol 2008;8:21.

19. EBSCO. Searching with Boolean Operators. https://help.ebsco. com/interfaces/EBSCO_Guides/EBSCO_Interfaces_User_Guide/ Searching_with_Boolean_Operators (accessed 13 Aug 2018).

20. Thomas $\mathrm{J}$, Harden A. Methods for the thematic synthesis of qualitative research in systematic reviews. BMC Med Res Methodol 2008;8:45.

21. Critical Appraisal Skills Programme. CASP Checklists. Oxford Centre for Evidence Based Medicine. https://casp-uk.net/casp-toolschecklists/ (accessed 13 Aug 2018).

22. Thorne S, Jensen L, Kearney MH, et al. Qualitative metasynthesis: reflections on methodological orientation and ideological agenda. Qual Health Res 2004:14:1342-65.

23. PRISMA. Flow Diagram Records identified through database searching. 2009 www.prisma-statement.org.

24. Jones SM. Emergency nurses' caring experiences with Mexican American patients. J Emerg Nurs 2008;34:199-204.

25. Terraza-Núñez R, Vázquez ML, Vargas I, et al. Health professional perceptions regarding healthcare provision to immigrants in Catalonia. Int J Public Health 2011;56:549-57.

26. Priebe S, Sandhu S, Dias S, et al. Good practice in health care for migrants: views and experiences of care professionals in 16 European countries. BMC Public Health 2011;11:187.

27. Priebe S, RÁ MB, Neele V, et al. Good practice in emergency care: views from practitioners. Brend R, ed. Migration and the EU, 2011:213-26.

28. Jensen NK, Norredam M, Draebel T, et al. Providing medical care for undocumented migrants in Denmark: what are the challenges for health professionals? BMC Health Serv Res 2011;11:154

29. Biswas D, Kristiansen M, Krasnik A, et al. Access to healthcare and alternative health-seeking strategies among undocumented migrants in Denmark. BMC Public Health 2011:11:560.

30. Dauvrin M, Lorant V, Sandhu S, et al. Health care for irregular migrants: pragmatism across Europe: a qualitative study. BMC Res Notes 2012;5:99.

31. Gullberg F, Wihlborg M. Nurses' experiences of encountering undocumented migrants in Swedish emergency healthcare. Int $J$ Migr Health Soc Care 2014;10:148-58.

32. Kietzmann D, Hannig C, Schmidt S. Migrants' and professionals views on culturally sensitive pre-hospital emergency care. Soc Sci Med 2015;138:234-40.

33. Ozolins L-L, Hjelm K. Nurses' experiences of problematic situations with migrants in emergency care in Sweden. Clin Eff Nurs 2003;7:84-93.

34. Hultsjö S, Hjelm K. Immigrants in emergency care: Swedish health care staff's experiences. Int Nurs Rev 2005;52:276-85.

35. Ahmad WI, Baker MR, Kernohan EE. General practitioners' perceptions of Asian and non-Asian patients. Fam Pract 1991:8:52-6.

36. Hwang U, Weber EJ, Richardson LD, et al. A research agenda to assure equity during periods of emergency department crowding. Acad Emerg Med 2011;18:1318-23.

37. Credé SH, Such E, Mason S. International migrants' use of emergency departments in Europe compared with non-migrants' use: a systematic review. Eur J Public Health 2018;28:61-73.
38. Porthé V, Vargas I, Sanz-Barbero B, et al. Changes in access to health care for immigrants in Catalonia during the economic crisis: Opinions of health professionals and immigrant users. Health Policy 2016:120:1293-303.

39. Taylor K. Asylum seekers, refugees, and the politics of access to health care: a UK perspective. Br J Gen Pract 2009;59:765-72.

40. World Health Organisation. Migration and health: key issues. 2018 http://www.euro.who.int/en/health-topics/health-determinants/ migration-and-health/migrant-health-in-the-european-region/ migration-and-health-key-issues\#292936 (accessed 17 Aug 2018)

41. Espinoza J. More than 300 different languages spoken in British schools, report says. Telegraph Newspaper 2015 https://www. telegraph.co.uk/education/educationnews/11761250/More-than300-different-languages-spoken-in-British-schools-report-says.html (accessed 19 Dec 2018).

42. Department of Health and Social Care. Health protection: Migrant health guide. https://www.gov.uk/topic/health-protection/migranthealth-guide (accessed 19 Dec 2018)

43. The King's Fund. What do we know about the impact of immigration on the NHS? 2018 https://www.kingsfund.org.uk/projects/verdict/ what-do-we-know-about-impact-immigration-nhs (accessed 20 Aug 2018).

44. Richardson LD, Babcock Irvin C, Tamayo-Sarver JH. Racial and ethnic disparities in the clinical practice of emergency medicine. Acad Emerg Med 2003;10:1184-8.

45. The World Medical Association. Declaration of Geneva. $1948 \mathrm{https} / / /$ www.wma.net/what-we-do/medical-ethics/declaration-of-geneva/ (accessed 31 Aug 2018)

46. Bowcott $\mathrm{O}$. Home Office scraps scheme that used NHS data to track migrants. The Guardian 2018 https://www.theguardian.com/society/ 2018/nov/12/home-office-scraps-scheme-that-used-nhs-data-totrack-migrants (accessed 19 Dec 2018).

47. Hamill M, McDonald L, Brook G, et al. Ethical and legal issues in caring for asylum seekers and refugees in the UK. Bull Med Ethics 2004:17-21.

48. Department of Health and Social Care. Guidance on implementing the overseas visitor hospital charging regulations. 2017 www. nationalarchives.gov.uk/doc/open-government-licence/.

49. Dayan M. The Nuffield Trust. The facts: EU immigration and pressure on the NHS. 2016 https://www.nuffieldtrust.org.uk/ resource/the-facts-eu-immigration-and-pressure-on-the-nhs\#areeu-immigrants-driving-current-pressure-on-the-nhs (accessed 20 Aug 2018).

50. Bowsher GM, Krishnan RA, Shanahan T, et al. challenges health of migrants in the UK. The Lancet 2014;2015:852-3.

51. Doctors of the World. Deterrence, delay and distress: the impact of charging in NHS hospitals on migrants in vulnerable circumstances. Doctors of the world. $2017 \mathrm{https}: / / \mathrm{www}$.doctorsoftheworld.org. uk/Handlers/Download.ashx?IDMF=2a7fc733-ceef-4417-9783d69b016ff74f.

52. Bulman M. NHS charging rules: Doctors and nurses accuse Government of 'deliberate cruelty' with upfront payments and ID checks. The Independent 2017 https://www.independent.co. uk/news/uk/home-news/nhs-charging-rules-doctors-nursesgovernment-id-checks-payments-home-office-hospitals-docs-notcops-a8014966.html (accessed 1 Sep 2018).

53. Creative Research. Qualitative Assessment of Visitor and Migrant use of the NHS in England Observations from the Front Line -Summary. Department of Health. 2013.

54. lacobucci G. Union vows to support NHS staff who refuse to act as "border guards". BMJ 2018;360:k471.

55. Sweileh WM, Wickramage K, Pottie K, et al. Bibliometric analysis of global migration health research in peer-reviewed literature (20002016). BMC Public Health 2018;18:777.

56. Burns R, Pathak N, Campos-Matos I, et al. Million Migrants study of healthcare and mortality outcomes in non-EU migrants and refugees to England: Analysis protocol for a linked population-based cohort study of 1.5 million migrants. Wellcome Open Res 2019;4:4 https:// doi.org/10.12688/wellcomeopenres.15007.1.

57. The Lancet. The UCL-Lancet Commission on Migration and Health: the health of a world on the move. https://www.thelancet.com/ commissions/migration-health (accessed 5 Dec 2018). 